\title{
Inhibition of O-GlcNAcase leads to elevation of O-GlcNAc tau and reduction of tauopathy and cerebrospinal fluid tau in rTg4510 mice
}

Nicholas B. Hastings ${ }^{1+}$, Xiaohai Wang ${ }^{2 \dagger}$, Lixin Song ${ }^{1 \dagger}$, Brent D. Butts ${ }^{3}$, Diane Grotz ${ }^{4}$, Richard Hargreaves ${ }^{5}$, J. Fred Hess ${ }^{1}$, Kwok-Lam Karen Hong ${ }^{1}$, Cathy Ruey-Ruey Huang ${ }^{1}$, Lynn Hyde ${ }^{1}$, Maureen Laverty ${ }^{3}$, Julie Lee ${ }^{1}$, Diane Levitan ${ }^{3}$, Sherry X. Lu', Maureen Maguire ${ }^{3}$, Veeravan Mahadomrongkul', Ernest J. McEachern ${ }^{6}$, Xuesong Ouyang ${ }^{1}$, Thomas W. Rosahl ${ }^{7}$, Harold Selnick ${ }^{8}$, Michaela Stanton ${ }^{1}$, Giuseppe Terracina ${ }^{1}$, David J. Vocadlo ${ }^{6}$, Ganfeng Wang ${ }^{5}$, Joseph L. Duffy ${ }^{{ }^{*}}$, Eric M. Parker ${ }^{1 *}$ and Lili Zhang ${ }^{1 *}$ (D)

\begin{abstract}
Background: Hyperphosphorylation of microtubule-associated protein tau is a distinct feature of neurofibrillary tangles (NFTs) that are the hallmark of neurodegenerative tauopathies. O-GlcNAcylation is a lesser known posttranslational modification of tau that involves the addition of $\mathrm{N}$-acetylglucosamine onto serine and threonine residues. Inhibition of O-GlcNAcase (OGA), the enzyme responsible for the removal of O-GlcNAc modification, has been shown to reduce tau pathology in several transgenic models. Clarifying the underlying mechanism by which OGA inhibition leads to the reduction of pathological tau and identifying translatable measures to guide human dosing and efficacy determination would significantly facilitate the clinical development of OGA inhibitors for the treatment of tauopathies.
\end{abstract}

Methods: Genetic and pharmacological approaches are used to evaluate the pharmacodynamic response of OGA inhibition. A panel of quantitative biochemical assays is established to assess the effect of OGA inhibition on pathological tau reduction. A "click" chemistry labeling method is developed for the detection of O-GlcNAcylated tau.

Results: Substantial (>80\%) OGA inhibition is required to observe a measurable increase in O-GlcNAcylated proteins in the brain. Sustained and substantial OGA inhibition via chronic treatment with Thiamet G leads to a significant reduction of aggregated tau and several phosphorylated tau species in the insoluble fraction of rTg4510 mouse brain and total tau in cerebrospinal fluid (CSF). O-GlcNAcylated tau is elevated by Thiamet G treatment and is found primarily in the soluble $55 \mathrm{kD}$ tau species, but not in the insoluble $64 \mathrm{kD}$ tau species thought as the pathological entity.

(Continued on next page)

\footnotetext{
*Correspondence: joseph_duffy@merck.com; ericmcparker@comcast.net;

Ilzh@icloud.com

${ }^{\dagger}$ Equal contributors

${ }^{9}$ Discovery Chemistry Merck Research Laboratories, Kenilworth, NJ, USA

${ }^{1}$ Department of Neuroscience, Kenilworth, NJ, USA

Full list of author information is available at the end of the article
} 
(Continued from previous page)

Conclusion: The present study demonstrates that chronic inhibition of OGA reduces pathological tau in the brain and total tau in the CSF of rTg4510 mice, most likely by directly increasing O-GlcNAcylation of tau and thereby maintaining tau in the soluble, non-toxic form by reducing tau aggregation and the accompanying panoply of deleterious post-translational modifications. These results clarify some conflicting observations regarding the effects and mechanism of OGA inhibition on tau pathology, provide pharmacodynamic tools to guide human dosing and identify CSF total tau as a potential translational biomarker. Therefore, this study provides additional support to develop OGA inhibitors as a treatment for Alzheimer's disease and other neurodegenerative tauopathies.

Keywords: Tau, OGA, O-GlcNAc, Alzheimer's disease, Tauopathy, Neurodegeneration

\section{Background}

Intra-neuronal accumulation of neurofibrillary tangles (NFTs) is one of the major pathological hallmarks of Alzheimer's disease. The main component of NFTs is tau, a microtubule-binding protein that becomes hyperphosphorylated and aggregates into paired helical filaments during disease development [1]. Tau pathology, or tauopathy, is also present in a number of other neurodegenerative diseases, including progressive supranuclear palsy (PSP), corticobasal degeneration, frontotemporal dementia and Pick's disease [2]. Dominant tau mutations have been identified that are associated with aggressive tauopathies, including frontotemporal dementia with Parkinsonism on chromosome 17 and PSP [3, 4]. These findings support a pathogenic role of tau in neurodegeneration and lead to the therapeutic hypothesis that reduction of tau pathology may be a viable approach to slow down the progression of diseases involving tauopathy.

Protein O-GlcNAcylation is a reversible posttranslational modification involving addition of a single $\mathrm{N}$-acetylglucosamine (O-GlcNAc) moiety onto the hydroxyl group of serine and threonine residues (reviewed by [5]). This modification is regulated by two enzymes in mammalian cells. O-GlcNAc transferase (OGT, EC 3.2.1.255) catalyzes the addition of O-GlcNAc to protein substrates and O-GlcNAcase (OGA, EC 3.2.1.169) catalyzes the hydrolytic removal of O-GlcNAc from proteins. Many cytoplasmic and nuclear proteins are subject to O-GlcNAcylation, and because this modification occurs on serine and threonine residues, it can potentially modulate protein phosphorylation directly on the same sites or indirectly on proximal sites [5].

The possible dynamic interplay between protein OGlcNAcylation and phosphorylation has led to the hypothesis that inhibition of the OGA enzyme would promote O-GlcNAcylation of tau, thereby attenuating tau hyperphosphorylation and providing therapeutic benefit for AD and other tauopathies [6]. In fact, several studies in which the potent and selective OGA inhibitor Thiamet $\mathrm{G}$ was administered to transgenic mice overexpressing human tau have demonstrated positive effects on tau pathology, tau phosphorylation (p-tau) and/or behaviors and phenotypes thought to be dependent on tau pathology ([7-9], also reviewed by [6]). Although these findings generally support OGA inhibition as a promising approach to regulate tau pathology, there are significant discrepancies regarding whether and by what mechanism OGA inhibition affects tau aggregation, phosphorylation and/or O-GlcNAcylation. These discrepancies have hindered the progression of OGA inhibitors into human clinical development [10]. In addition, information and tools to guide human dosing of OGA inhibitors are very limited. The degree of OGA inhibition required to reduce tau pathology is unknown, and there are no translational biomarkers or sensitive, quantitative, high throughput assays that measure OGA inhibition and its effect on tau pathology in humans. Clarifying the mechanism by which OGA inhibition reduces tau pathology and addressing these translational gaps will greatly facilitate further advancement of this target for the treatment of tauopathies.

To further establish the mechanism of OGA inhibitors as a potential treatment for tauopathies and to develop transitional tools, we undertook a systematic assessment of the effects of the OGA inhibitor Thiamet $G$ in rTg4510 mice. This mouse model of tauopathy has several features that facilitate the evaluation of potential therapeutic treatments [11-14]. We utilized a panel of previously developed high throughput, quantitative assays for various species of tau [13], which enabled us to detect pathological tau development at an early age in rTg4510 mice and to conduct well-powered studies to mitigate the high inter-animal variability inherent in this model. In addition, several novel assays were developed to measure O-GlcNAcylation of proteins in the brain, including an assay to directly measure O-GlcNAcylation of tau. These studies provide the first description of the pharmacology of OGA inhibition required for reduction of tauopathy, identify decreases in CSF tau as a translatable biomarker of pathological tau reduction by OGA inhibition, and confirm direct O-GlcNAcylation of tau as the likely mechanism by which OGA inhibition reduces pathological tau. Taken together, these studies pave a 
path forward for further development of OGA inhibitors to treat tauopathy in humans.

\section{Results}

\section{Effect of OGA inhibition on O-protein levels}

A sensitive, quantitative, high throughput MesoScale Diagnostics (MSD) sandwich immunoassay was developed to examine the effect of OGA inhibition on global protein O-GlcNAcylation (hereafter referred to as Oprotein). This assay was validated using HEK293 cells treated with the potent and selective OGA inhibitor Thiamet G [15]. In these experiments, Thiamet G treatment led to a dose-dependent increase of O-protein, with an $\mathrm{EC}_{50}$ of $32 \mathrm{nM}$ and a maximal O-protein elevation of 5- to 6-fold over levels observed in vehicletreated cells (Fig. 1). The $\mathrm{EC}_{50}$ value and maximal $\mathrm{O}$ protein elevation are consistent with the values previously reported after Thiamet G treatment of PC12 cells [15], but the quantitative precision, assay window and throughput of our MSD assay are significantly greater than the densitometric quantitation of Western blots used in previous studies. These advantages of the MSD assay permitted much more facile and accurate analysis of large numbers of samples from the subsequent animal studies.

This assay was used in combination with genetic and pharmacological approaches to determine the dose of Thiamet $G$ and the consequent degree of inhibition of OGA required for a therapeutic effect. Since constitutive knockout of the OGA gene is perinatal lethal [16], we developed an inducible OGA knockdown (OGA iKD) mouse model to study the effect of reduction of OGA enzymatic activity on brain O-protein levels (Additional file 1). After shRNA-mediated OGA knockdown for 10 days, reduction of OGA mRNA expression was observed across all tissues examined, with an average reduction of $70-80 \%$ (Additional file 2). Binding of $\left[{ }^{3} \mathrm{H}\right]$ Thiamet $\mathrm{G}$ in brain homogenates revealed an $80 \%$ reduction of OGA enzyme levels in OGA iKD mice compared to wild type mice (Fig. 2a), consistent with the magnitude of OGA mRNA reduction. Despite the substantial reduction of OGA mRNA and enzyme levels, the OGA iKD mice were normal with no overt phenotype. Interestingly, only a modest 1.4 -fold increase of total O-protein was observed in the brains of OGA iKD mice despite the $80 \%$ reduction of OGA enzyme levels (Fig. 2b).

Pharmacological modulation of OGA activity was examined by treating mice with a single oral dose of either 10 or $500 \mathrm{mg} / \mathrm{kg}$ Thiamet G. Pharmacokinetic analysis showed a dose-dependent increase of Thiamet $G$ in plasma and brain (Fig. 3a), although the compound has relatively poor brain penetration (brain to plasma ratio $<0.1)$. To determine the extent of brain OGA inhibition at these doses, we measured changes in O-protein levels in the brain. Administration of Thiamet $\mathrm{G}$ at 10 and $500 \mathrm{mg} / \mathrm{kg}$ led to a 1.7 - and 4-fold increase of brain total O-protein, respectively (Fig. 3b). These data, along with the modest 1.4-fold increase of brain O-protein observed after $80 \%$ knockdown of brain OGA levels, suggest that a $500 \mathrm{mg} / \mathrm{kg}$ dose of Thiamet G is needed to significantly increase O-GlcNAc modification of brain

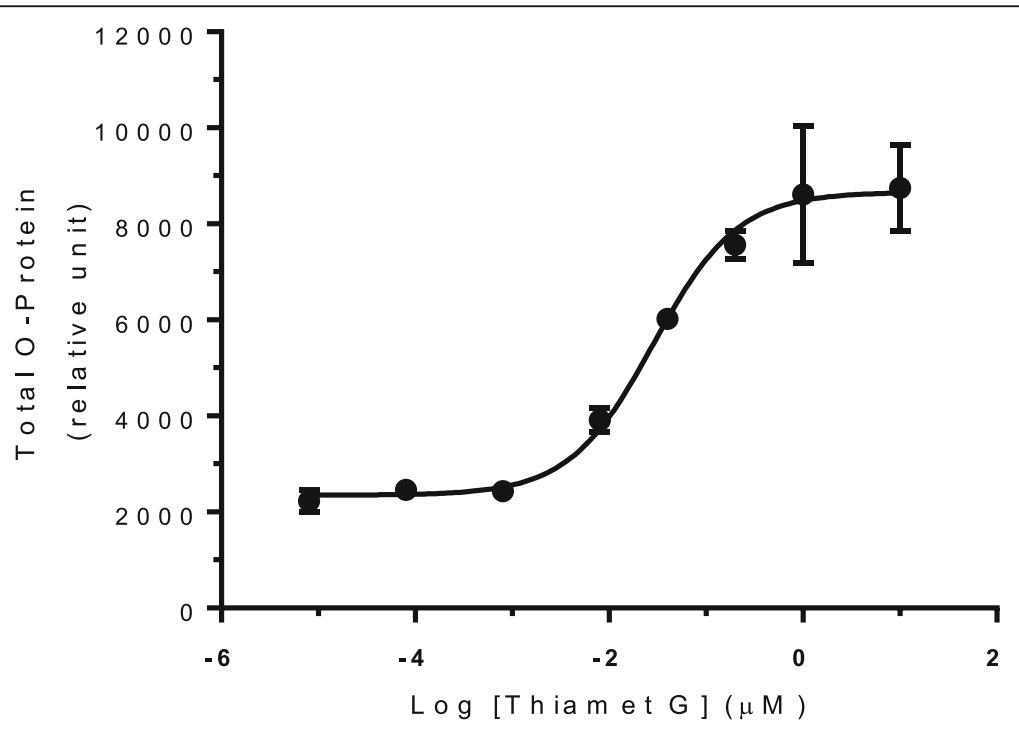

Fig. 1 Dose-dependent increase of total O-protein in HEK293 cells treated with Thiamet G. A quantitative sandwich immunoassay (see Methods) was used to detect O-protein after treating the cells with various concentrations of Thiamet $\mathrm{G}$ for $6 \mathrm{~h}$. The data shown are the mean \pm standard error of the mean (SEM) from a single experiment performed in triplicate and are representative of three independent experiments 

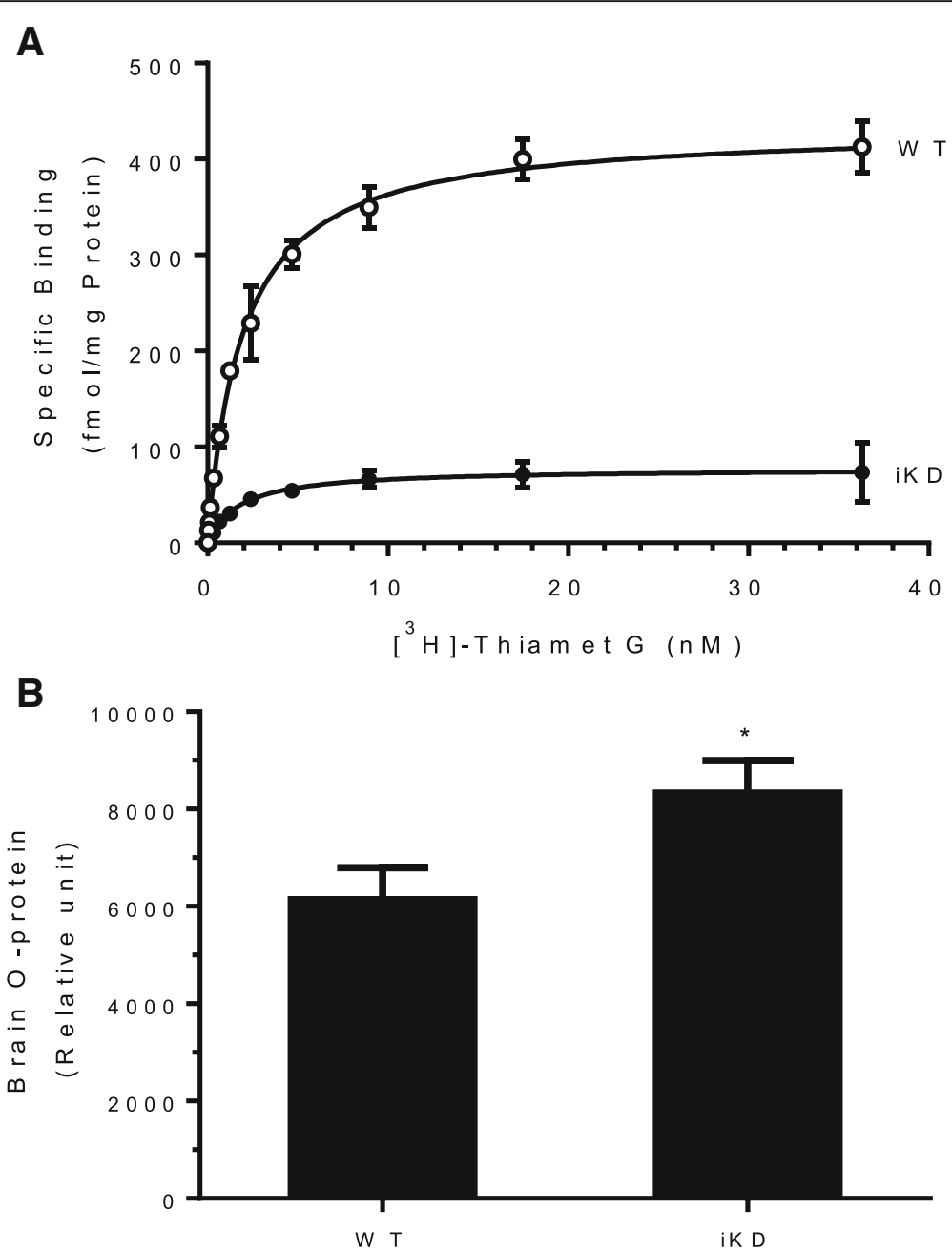

Fig. 2 Determination of OGA enzyme and O-protein levels in OGA iKD mice. a Binding of $\left[^{3} \mathrm{H}\right]$ Thiamet $\mathrm{G}$ in brain homogenates prepared from WT $(n=5)$ and OGA iKD $(n=4)$ mice was determined as described in Methods. Individual saturation binding curves were performed using total brain homogenates prepared from each animal and the data shown are the mean \pm standard deviation of values for each group of animals. The $K_{D}$ of $\left[{ }^{3} H\right]$ Thiamet $G$ binding to OGA was similar in WT and OGA iKD mouse brain ( $K_{D}=1.7 \mathrm{nM}$ and $1.9 \mathrm{nM}$, respectively), while the $B_{\text {max }}$ values were reduced by $80 \%$ in the OGA iKD mouse relative to the WT mouse $(433 \mathrm{fmol} / \mathrm{mg}$ protein and $78 \mathrm{fmol} / \mathrm{mg}$ protein, respectively). b Total Oprotein in brain homogenates from WT $(n=5)$ and OGA iKD mice $(n=5)$ was measured by a quantitative sandwich immunoassay as described in Methods. Brain O-protein levels were 1.4-fold higher in OGA iKD mice relative to the WT mice. The data shown are the mean \pm SEM. Each sample was assayed in duplicate. ${ }^{*} p=0.048$ (t-test)

proteins. Therefore, this dose was used in the subsequent chronic study.

\section{Effect of OGA inhibition on tauopathy in $\mathrm{rTg} 4510$ mice}

The rTg4510 mouse model uses the $\mathrm{Ca}^{2+}$-calmodulin kinase II promoter to overexpress human 0N4R tau carrying the P301L mutation [11]. This model recapitulates several important features of tau pathology observed in the brains of $\mathrm{AD}$ patients, including distribution in forebrain regions, multiple post-translational modifications of tau and elevated CSF tau [11, 13]. However, this model is also characterized by high inter-animal variability, an issue that may have contributed to variable OGA inhibitor effects in this model. Therefore, we mitigated this issue by using only female animals [13] and adequately powering the study to detect a relatively modest $30 \%$ effect of chronic treatment with $500 \mathrm{mg} / \mathrm{kg} /$ day Thiamet G on tauopathy in $\mathrm{rTg} 4510$ mice (see Methods). Two treatment durations of 4 weeks (from 12 to 16 weeks of age) or for 8 weeks (from 8 to 16 weeks of age) were studied to explore the time frame required to observe effects of OGA inhibition on tau pathology in the rTg4510 model. These ages and durations of treatment were chosen because they represent the early to middle stages of tauopathy in the rTg4510 model and thus correspond to the stages at which treatment is most 

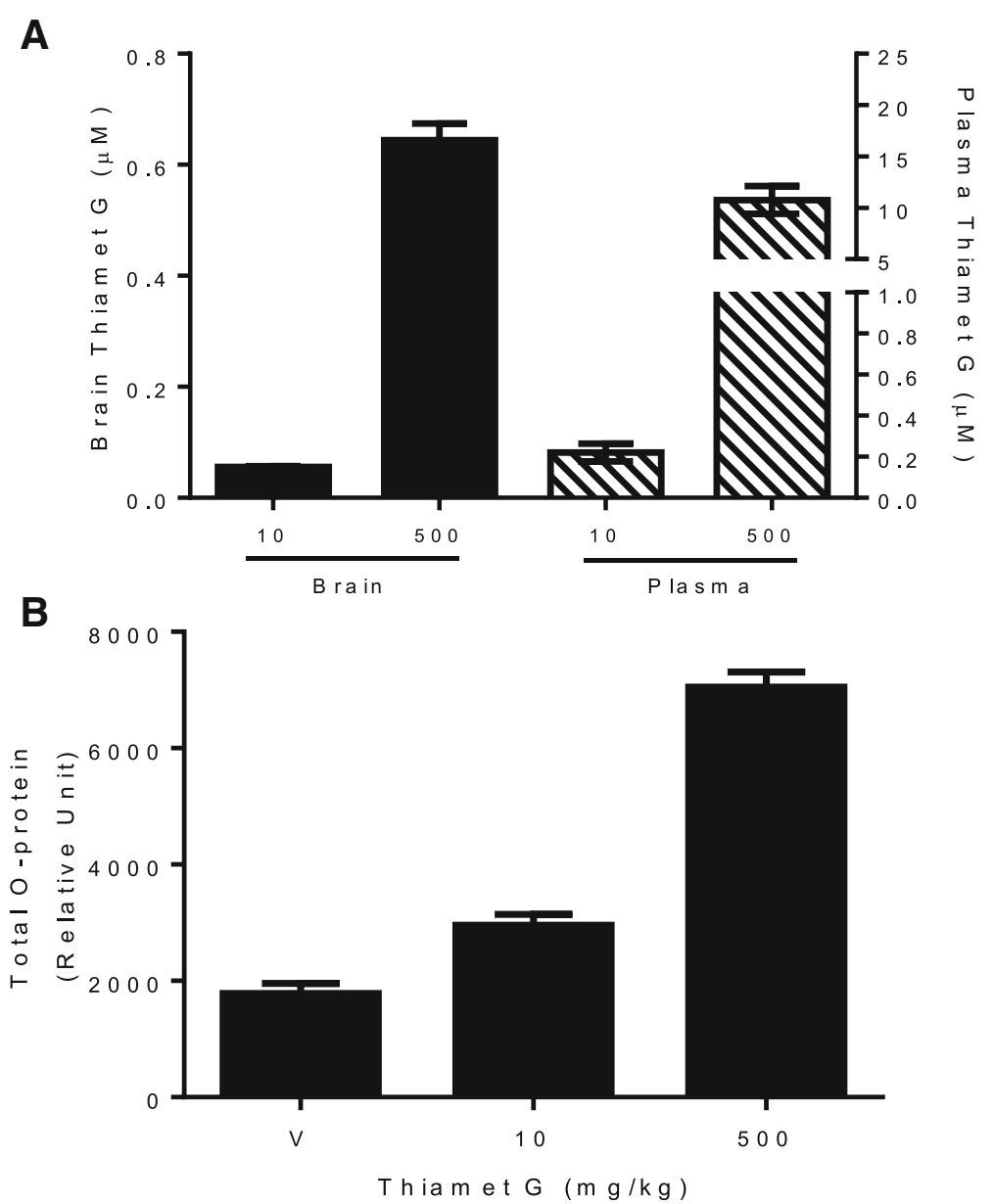

Fig. 3 Brain O-protein levels following acute Thiamet G treatment. C57BL6 mice ( $n=8$ per group) were given a single oral dose of vehicle (water) or Thiamet $\mathrm{G}$ at 10 or $500 \mathrm{mg} / \mathrm{kg}$. Brain and plasma were collected $6 \mathrm{~h}$ after dosing. a Concentrations of Thiamet $\mathrm{G}$ in plasma (right) and brain (left). $\mathbf{b}$ Elevation of O-protein in total brain homogenates after Thiamet $\mathrm{G}$ treatment. All data shown are the mean \pm SEM. Each sample was assayed in duplicate

likely to be effective, both in this model and in humans. The compound was well tolerated, and no overt adverse effects were observed in any treatment group. Animals in all groups gained weight as expected and there were no significant differences in food intake or body weight between treatment groups (Fig. 4a and b). Pharmacokinetic and pharmacodynamic analysis showed comparable terminal drug concentration in plasma and brain (Fig. 4c) and comparable elevation of brain total Oprotein (Fig. 4d) in both Thiamet G-treated groups.

The effect of chronic Thiamet G treatment on tauopathy in $\mathrm{rTg} 4510$ mice was assessed by measuring various tau species in the insoluble fraction of brain homogenates. Dramatic increases of phosphorylated tau (recognized by anti-phosphothreonine (anti-pThr) and PHF6 antibodies) and aggregated tau were observed as the mice aged from 8 to 16 weeks (Fig. 5a-c; compare the increase in baseline levels of these tau species between 8 and 12 weeks of age and the further increase in the vehicle-treated group at 16 weeks of age). Insoluble species of hyperphosphorylated, aggregated tau are characteristic of tauopathy $[2,17]$, and these data thus indicate marked disease progression in the $\mathrm{rTg} 4510$ model during this period [13]. Compared to vehicle-treated rTg4510 mice, treatment with $500 \mathrm{mg} / \mathrm{kg} /$ day of Thiamet G for 8 weeks (from 8 to 16 weeks of age) led to a significant reduction of accumulated insoluble tau aggregates and pathological hyperphosphorylated tau species recognized by PHF6 and anti-pThr. Thiamet G treatment for 4 weeks (from 12 to 16 weeks of age) also led to a reduction of these pathological tau species, although the reduction did not reach statistical significance (Fig. 5a-c). Hyperphosphorylated tau species recognized by antibodies AT8 (pS202/pT205), AT270 (pT181) and AT180 (pT231) also showed a reduction in the brain insoluble fraction after Thiamet $G$ treatment similar to that 


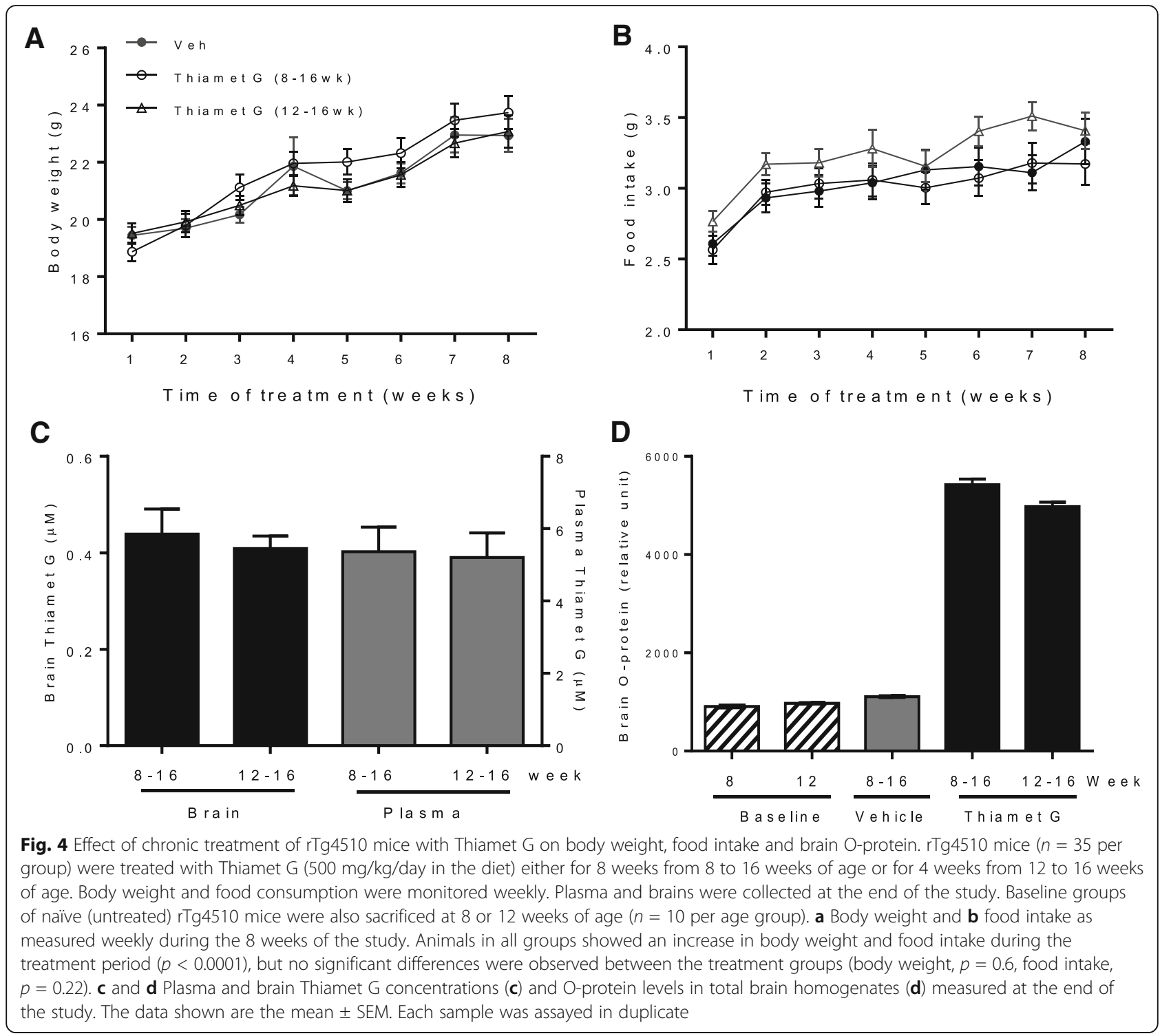

observed for species recognized by PHF6 and pThr (data not shown). In addition, a close correlation between different pathological tau species was observed despite large variations in each treatment cohort (Fig. 5e and f). There was no significant change in total tau in the insoluble fraction between 8 and 16 weeks of age, nor were total tau levels affected by Thiamet $G$ treatment (Fig. 5d).

As previously reported [13], CSF total tau in 16 week old rTg4510 mice was elevated above the baseline levels in 8 and 12 week old mice (Fig. 6a), again indicating significant progression of tauopathy in this time frame. The rise of CSF total tau was reduced significantly after treatment of $\mathrm{rTg} 4510$ mice with $500 \mathrm{mg} / \mathrm{kg} /$ day of Thiamet G for 8 weeks from 8 to 16 weeks of age, but no statistically significant change was observed after treatment for
4 weeks from 12 to 16 weeks of age (Fig. 6a). Similar effects of Thiamet G treatment on CSF pT181 tau were observed, although the reduction of CSF pT181 tau after 8 weeks of treatment did not reach statistical significance (Fig. 6b). Once again, the change in CSF pT181 tau showed strong correlation with that of total tau (Fig. 6c). Overall, the effect of Thiamet G on the elevated CSF total tau and pT181 tau in rTg4510 mice closely mirrored the effects of the compound on various tau species in the insoluble fraction of brain (cf. Figs. 5 and 6).

\section{Detection of O-GIcNAc-tau (O-tau) after Thiamet G treatment}

To further understand the mechanism by which OGA inhibition reduces tauopathy, we assessed whether tau 


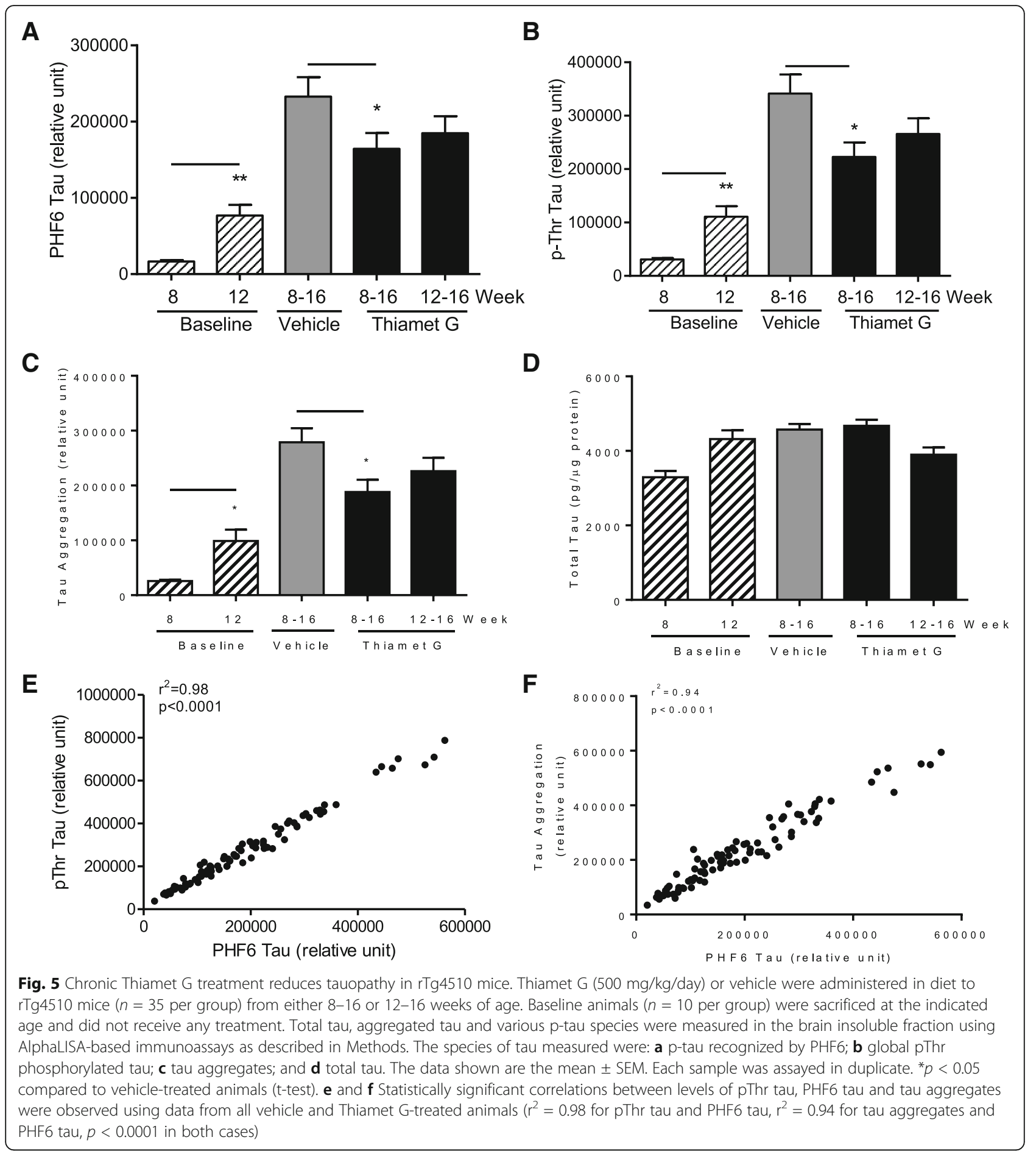

was O-GlcNAcylated in $\mathrm{rTg} 4510$ mouse brain and then investigated the impact of OGA inhibition on O-tau levels. Although the antibody-based detection of O-tau has been described in the literature [7, 18], we were not able to detect O-tau in rTg4510 brain using anti-OGlcNAc antibodies such as RL2 (J. Lee and G. Terracina, unpublished data) or the anti-O-tau antibody 3925
(Additional file 3). Thus, we developed a gel-based Otau assay using "click" chemistry with the Click-i $\mathrm{T}^{(\mathrm{R})}$ labeling kit. The overall scheme of this assay is shown in Fig. $7 \mathrm{a}$ and is described in detail in Methods. This assay identified a specific TAMRA-labeled band with several characteristics consistent with O-tau, namely that it was immunoprecipitated by an anti-tau antibody, detected by 

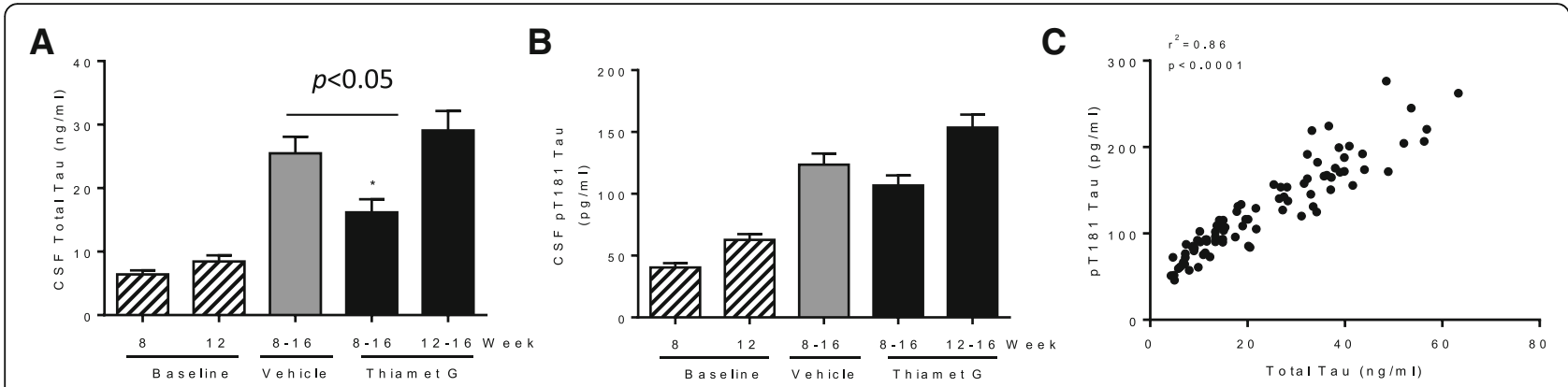

Fig. 6 Effects of chronic Thiamet G treatment of $\mathrm{rTg} 4510$ mice on CSF tau. Thiamet G (500 mg/kg/day) or vehicle were administered in diet to rTg4510 mice ( $n=35$ per group) from either $8-16$ or 12-16 weeks of age. Baseline animals ( $n=10$ per group) were sacrificed at the indicated age and did not receive any treatment. Eight weeks of treatment with Thiamet G treatment significantly reduced CSF total tau (a; ${ }^{*} p<0.05$ by t-test) and CSF pT181 tau (b), although the latter effect did not reach statistical significance. CSF total tau and pT181 tau were measured as described in Methods. The data shown are the mean \pm SEM. Each sample was assayed in duplicate. c Statistically significant correlation of CSF total tau and pT181 tau in vehicle and Thiamet G-treated groups $\left(r^{2}=0.86, p<0.0001\right)$

an anti-tau antibody in Western blot, co-migrated at the known molecular weight $(55 \mathrm{kDa})$ of soluble human tau, and was seen in $\mathrm{rTg} 4510$ mice that overexpress human tau, but not in wild type mice (Fig. 7b). The identity of this band as $\mathrm{O}$-tau was further confirmed by its resistance to PNGase F, which removes only N-linked glycans, and its sensitivity to $\beta$-elimination, which removes $\mathrm{O}$ linked glycans (Fig. 7c). These data thus demonstrate the successful detection of O-tau in $\mathrm{rTg} 4510$ mouse brain.

Using this gel-based assay, we examined the effect of Thiamet G on O-tau in different $\mathrm{rTg} 4510$ brain
A

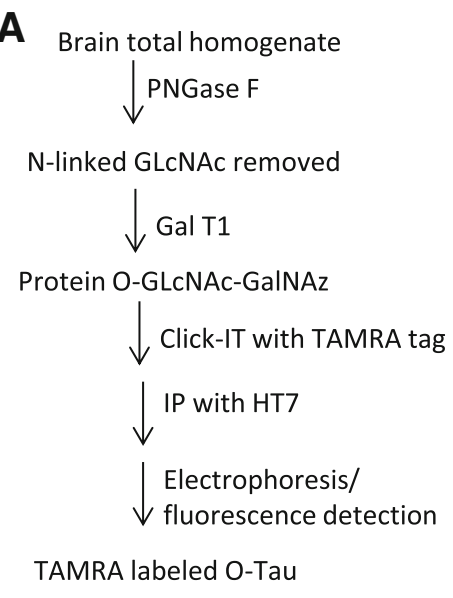

B
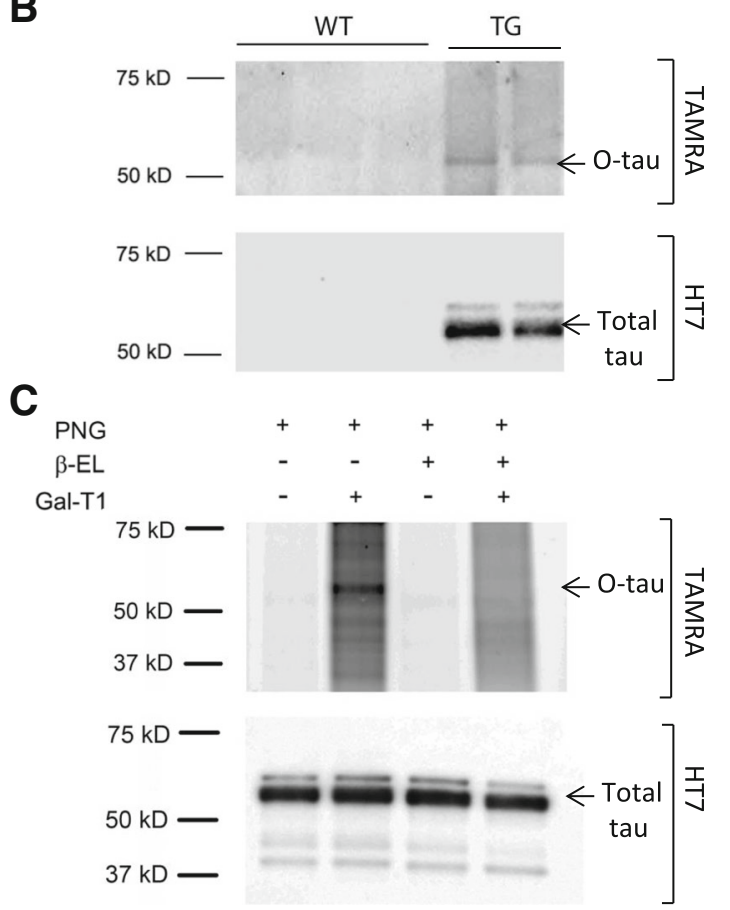

Fig. 7 Validation of the "click" chemistry method for detection of O-tau. a Flow chart describing the procedure for O-tau detection (see Methods for further details). $\mathbf{b}$ Detection of a $55 \mathrm{kDa}$ TAMRA-labeled protein in rTg4510 mouse brain homogenate (upper panel) that is recognized by the HT7 anti-tau antibody (lower panel). Note that this putative human O-tau band migrates at the known molecular weight of soluble human tau (55 kDa) and was seen only in brain samples from rTg4510 mice that overexpress human tau (lanes labeled TG), but not in brain samples from wild type C57BL6 mice (lanes labeled WT). c The 55 kDa TAMRA labeled band was insensitive to PNGase F treatment (PNG), required Gal-T1 treatment and was abolished by $\beta$-elimination ( $\beta$-EL), thus further validating this band as O-tau 
fractions. O-tau was significantly elevated by $500 \mathrm{mg} / \mathrm{kg} /$ day Thiamet $G$ treatment from 8 to 16 weeks, while total tau was unchanged (Fig. 8a). At 16 weeks of age, tau in rTg4510 mouse brain starts to shift from a $55 \mathrm{kDa}$ species enriched in the soluble fraction to a hyperphosphorylated $64 \mathrm{kDa}$ species that is enriched in the insoluble fraction [13]. Interestingly, O-GlcNAc was mostly associated with the soluble $55 \mathrm{kDa}$ tau species, but not the insoluble, hyperphosphorylated $64 \mathrm{kDa}$ tau species (Fig. 8a). Quantitation of the gels demonstrated a 4-5 fold increase of O-tau in the brain homogenate and soluble fraction and a smaller 2.8-fold increase of $\mathrm{O}$-tau in the insoluble fraction after Thiamet $G$ treatment, the latter being due primarily to the presence of some $55 \mathrm{kDa}$ soluble tau in the insoluble fraction (Fig. 8b).

\section{Discussion}

Several previous reports have suggested that OGA inhibition represents a promising treatment for neurodegenerative diseases characterized by tauopathy [7-9] These previous studies all concluded that chronic treatment with the potent and selective OGA inhibitor Thiamet $G$ leads to a reduction of pathological tau in transgenic mice that overexpress human tau. Some studies also demonstrated positive effects of chronic Thiamet G treatment on various behaviors and phenotypes thought to be dependent on pathological tau.

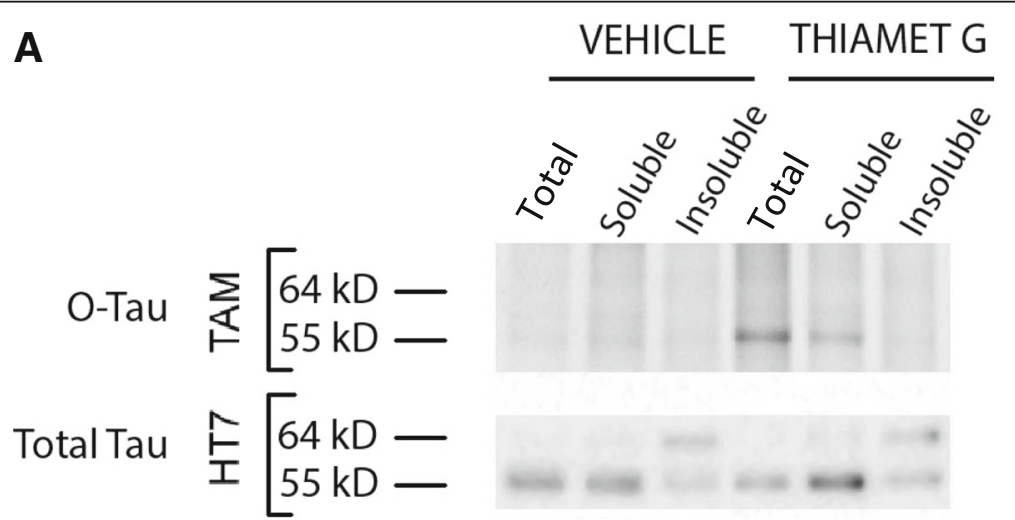

B

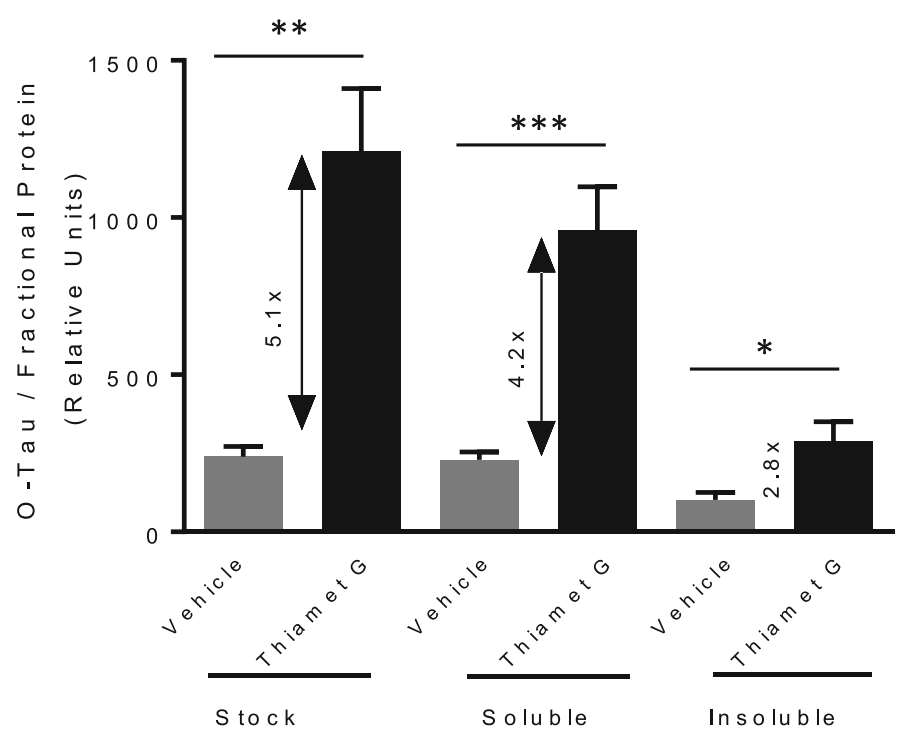

Fig. 8 Thiamet G treatment increases O-tau levels. rTg4510 mice were treated with Thiamet G (500 mg/kg/day) for 8 weeks from 8 to 16 weeks of age. Brains were harvested at the end of study to prepare total brain homogenate, soluble and insoluble fractions. a Thiamet $\mathrm{G}$ treatment led to elevated O-tau in the total brain homogenate and soluble fractions as detected by TAMRA (TAM) labeling, but had no effect on total tau as detected by HT7 antibody on Western blots (HT7). The data shown are from one vehicle and one Thiamet G-treated animal and are representative of 5 animals in each group. b Quantification of O-tau normalized to total tau from the data shown in $\mathbf{a}$. Unpaired t-test was used for comparison of vehicle and Thiamet $\mathrm{G}$ treatment $p=0.0013,0.0008$ and 0.014 for brain stock, soluble and insoluble fractions, respectively 
The results of our study are generally in agreement with these previous findings. Indeed, chronic treatment of $\mathrm{rTg} 4510$ mice with $500 \mathrm{mg} / \mathrm{kg}$ Thiamet $\mathrm{G}$ for 8 weeks (from 8 to 16 weeks of age) led to a significant reduction of several species of tau associated with tauopathy in the brain insoluble fraction. Four weeks of chronic Thiamet G treatment (from 12 to 16 weeks of age) showed qualitatively similar, albeit nonsignificant, effects. This is consistent with previous studies showing a progressive increase in the effects of OGA inhibition with increased treatment time [8, 9]. Alternatively, the reduced effect may be due to the fact that tauopathy is more advanced between 12 and 16 weeks of age and thus less amenable to OGA inhibitor treatment. The $500 \mathrm{mg} / \mathrm{kg}$ dose of Thiamet G was chosen because both genetic knockdown and preliminary pharmacological studies suggested that virtually complete inhibition of OGA is required to significantly increase brain O-protein levels in the rTg4510 mouse model. As expected, this dose of Thiamet $\mathrm{G}$ achieved complete inhibition of brain OGA and resulted in a $\sim 5$-fold increase in brain O-protein levels as assessed by a sensitive, high throughput assay developed for this study. The novel finding that virtually complete inhibition of OGA is required for a measurable pharmacodynamic effect and the development of a sensitive, high throughput assay for measurement of O-protein levels will greatly facilitate dose selection and quantitation of OGA inhibition in human clinical trials. The high degree of OGA inhibition required to detectably change brain O-protein levels suggests that OGA activity is tightly regulated to ensure the homeostasis of protein O-GlcNAcylation. Regulatory processes that compensate for the effects of OGA inhibition include substrate accumulation and an increase of OGA expression (Additional file 4); in contrast, no change in OGT levels was observed (data not shown). No overt phenotypes were observed either in the inducible OGA knockdown mice or after chronic treatment with Thiamet G, providing initial evidence that substantial OGA inhibition is well tolerated.

Although there is a consensus that OGA inhibition reduces pathological tau, the mechanism by which OGA inhibitors achieve this effect is unclear, and this uncertainty has hindered the advancement of OGA inhibitors for the treatment of tauopathies [10]. One proposal is that tau is not normally modified by $\mathrm{O}$ GlcNAc and that OGA inhibition influences tau pathology via an indirect mechanism, e.g. by altering OGlcNAcylation of proteins other than tau itself [8]. The data in the present study do not support this proposal. By employing a novel O-GlcNAc detection method involving "click" GalNAz derivatization coupled with TAMRA labeling, we clearly demonstrated
O-GlcNAc modification of tau after chronic treatment of rTg4510 mice with Thiamet G. Our results are consistent with previous studies that used O-tau specific antibodies to demonstrate O-GlcNAcylation of tau and elevation of O-tau upon Thiamet G treatment $[7,9]$. The conclusion that tau is not directly OGlcNAcylated was based on an inability to measure O-tau with antibody 3925 [8]. In our hands, antibody 3925 can detect high levels of O-tau (e.g. when HEK293 cells are co-transfected with tau and OGT and treated with Thiamet G), but does not have sufficient sensitivity to detect the low levels of O-tau in brain homogenates from $\mathrm{rTg} 4510$ mice under normal conditions or after treatment with Thiamet G (see Additional file 3). While further work is required to clarify the conflicting results with antibody 3925 [7, 19], the independent detection of O-tau by click chemistry labeling suggests that an increase in O-GlcNAcylation of tau is the most parsimonious explanation for the ability of OGA inhibition to reduce tau pathology in $\mathrm{rTg} 4510$ mice. As concluded previously, however [8], we cannot completely rule out the possibility that increased $\mathrm{O}$ GlcNAcylation of proteins other than tau may also contribute to the efficacy of Thiamet $\mathrm{G}$.

A reciprocal relationship between O-GlcNAcylation and phosphorylation of proteins has commonly been cited as the mechanism for OGA inhibitor effects $[5,15]$. Previous studies have suggested that OGA inhibition (and the presumed increase in tau O-GlcNAcylation) reduces tau phosphorylation after acute but not chronic treatment $[7,15,20]$; reduces tau phosphorylation [9] or total tau [7, 20] only in the pathological $64 \mathrm{kDa}$, sarkosyl-insoluble fraction; or bi-directionally alters the levels of various phosphorylated forms of tau [21]. The present study does in fact demonstrate reduction of several phosphorylated tau species as well as global tau phosphorylation in the insoluble fraction of brain homogenates after chronic Thiamet $\mathrm{G}$ treatment. However, several observations do not support a reciprocal interplay between O-GlcNAcylation and phosphorylation of specific amino acid residues of tau as the mechanism by which OGA inhibition reduces tau pathology. OGA inhibition reduces phosphorylation of the insoluble $64 \mathrm{kDa}$ tau species, but O-GlcNAcylated tau was detected primarily in the $55 \mathrm{kDa}$ tau species (present study, $[9,15,22]$ ). In addition, several phosphorylated species of tau (PHF6 tau, pThr tau, pT181 tau, pS202/pT205 tau and pT231 tau) were reduced in the insoluble fraction of brain after OGA inhibition, and the levels of these phosphorylated tau species were highly correlated across all animals and treatment groups. These results are consistent with our previous finding that many post-translationally modified forms of tau are highly 
correlated with one another throughout the lifespan of rTg4510 mice [13] and may suggest that OGA inhibition has a widespread rather than a discrete effect on phosphorylation and other post-translational modifications of tau (see below). Finally, it has recently been shown that very few of the known tau phosphorylation sites are modified by O-GlcNAc, either under normal physiological conditions [19] or after treatment of rTg4510 mice with Thiamet G [23] Even when tau and OGT are overexpressed in E. coli, only $\sim 1.5$ O-GlcNAc residues are detected per tau molecule [24]. Nevertheless, it remains formally possible that OGlcNAcylation reciprocally reduces tau phosphorylation at one or a very few specific sites that are critical in driving tau into an insoluble, aggregated, pathological state, and that these O-GlcNAc modifications are thus present at low and undetectable levels in the insoluble fraction.

It has also been proposed that the addition of polar OGlcNAc moieties to tau reduces the propensity of tau to aggregate, as shown in in vitro experiments [7, 22]. OGlcNAcylation has also been shown to reduce the aggregation propensity of other proteins such as $\alpha$-synuclein and polyhomeotic $[25,26]$. However, these in vitro aggregation studies used recombinant or synthetic proteins, which may have distinct sites and stoichiometry of O-GlcNAc modification compared to the native proteins in vivo. The present study demonstrates that chronic OGA inhibition reduces tau aggregates in the brains of $\mathrm{rTg} 4510$ mice, thus adding in vivo validation to the in vitro results. In agreement with recent results obtained with a novel O-tau antibody [9], we also found that OGlcNAc was primarily associated with the soluble $55 \mathrm{kDa}$ tau species, but not the insoluble $64 \mathrm{kD}$ pathological tau species. This argues that O-GlcNAc modification maintains tau in a non-pathological, unaggregated state with limited post-translational modifications $(55 \mathrm{kDa})$ and prevents the formation of insoluble, aggregated, highly modified pathological tau $(64 \mathrm{kD})$. While reduction of the aggregation propensity of tau is the most plausible explanation, additional work is necessary to better understand the molecular mechanism by which OGA inhibition reduces formation of pathological tau.

The varying conclusions reached in different studies regarding the potential mechanisms by which OGA inhibition reduces tau pathology may largely be attributed to the different methods and readouts used [7-9, 15, 24]. Different transgenic mouse models have been used to test the effects of OGA inhibition, and there is significant variability in age-related tau pathology development within and between the various animal models. We compensated for this variability by using a large number of female animals per treatment group to sufficiently power our analysis [13]. In addition, the high throughput immunoassays employed in this study are much more robust in detecting modest effects of OGA inhibition on various tau species than the Western blot methods used in other studies. Furthermore, the brain homogenate used in many studies in which p-tau species were measured $[7,20]$ is a more heterogeneous pool of different tau species than the soluble and insoluble brain fractions we used here $[7,13,20]$.

It has long been known that CSF total tau and p-tau are elevated in $\mathrm{AD}$ patients compared to age-matched controls [27]. In rTg4510 mice, CSF total tau also displays age-dependent changes during the accumulation of pathological tau in the brain $[12,13]$. This study reports for the first time an effect of OGA inhibitor treatment on CSF tau levels. Similar to the reduction of pathological species of tau in the brain, we observed a significant reduction of CSF total tau when $\mathrm{rTg} 4510$ mice were treated for 8 weeks with Thiamet G. In a shorter 4 week treatment paradigm, Thiamet $\mathrm{G}$ administration did not alter CSF total tau, again consistent with the less robust reduction in pathological tau in the brain achieved in this time frame. It is also interesting to note the strong correlation between CSF total tau and pT181 tau in response to OGA inhibition. Even though the reduction of pT181 tau did not reach statistical significance, the correlation between CSF total tau and pT181 tau suggests that these two endpoints reflect effects of OGA inhibition on the same pool of tau in CSF. Therefore, CSF total tau may serve as an important translational biomarker for OGA inhibitor development.

The results of this study clarify the mechanism by which OGA inhibition reduces pathological tau and describes translational knowledge and tools that will facilitate human clinical development of OGA inhibitors. The treatment paradigm (i.e. treatment from 8 to 16 weeks of age) was optimized to maximize the window to observe effects of OGA inhibition, allow detection of the earliest stages of pathological tau development, and to assess treatment effects at these early stages of pathology, a time frame in which efficacy of OGA inhibition (or any tau-based therapy) is likely to be most effective. Neurofibrillary tangle pathology and neurodegeneration in $\mathrm{rTg} 4510$ mice are not well-developed by 16 weeks of age [14], thus providing minimal or no window to observe effects of Thiamet $G$ on these parameters. In a study with the OGA inhibitors MK-8719 and Thiamet G to be published separately, reduction of neurofibrillary tangle pathology and neurodegeneration were observed after treatment between 8 and 20 weeks of age [28]. Furthermore, the $64 \mathrm{kDa}$ insoluble tau species measured in this study has been shown to correlate well with neurofibrillary tangle pathology [14]. 
We have previously shown that tauopathy in rTg4510 mice results from a more or less simultaneous repertoire of events, including conversion of tau from a soluble $55 \mathrm{kDa}$ species to an insoluble $64 \mathrm{kDa}$ species, multiple post-translational modifications (e.g. phosphorylation, acetylation, nitration, ubiquitination), impaired proteostasis, aggregation and NFT formation [13]. A corollary of this notion is that an ideal treatment for tauopathy should lead to a reduction of all these features, and indeed OGA inhibition appears to fulfill this criterion. Ongoing clinical trials with OGA inhibitors (e.g. [29]) will provide additional insight into the potential of this mechanism to reduce tauopathy.

\section{Conclusion}

The present study demonstrates that nearly complete inhibition of OGA via chronic treatment with Thiamet G reduces both pathological tau in the brain and total tau in the CSF of rTg4510 mice, thereby providing additional evidence that OGA inhibition may represent a safe and effective treatment for Alzheimer's disease and other neurodegenerative diseases characterized by tauopathy. We have demonstrated that tau itself is O-GlcNAcylated and that OGA inhibition most likely reduces pathological tau via a direct effect to increase O-tau and maintain tau in a soluble, unaggregated, non-pathogenic form. This added clarity around the mechanism by which OGA inhibition reduces tauopathy, the demonstration that nearly complete inhibition of OGA is required to achieve a measurable pharmacodynamic effect (increase in O-protein), the development of sensitive high throughput assays for detection of this pharmacodynamic effect and the identification of CSF total tau as a potential translational biomarker will support the clinical development of OGA inhibitors.

\section{Methods}

\section{Reagents}

Thiamet $G$ was synthesized as described [15]. Tritiated Thiamet $G$ was prepared from intermediate $\mathbf{1}$ by the scheme outlined below [30]. Reduction of the aldehyde of intermediate $\mathbf{1}$ using sodium borohydride $\left[{ }^{3} \mathrm{H}\right]$ followed by deprotection and purification gave $\left[{ }^{3} \mathrm{H}\right]$ Thiamet $\mathrm{G}$ in high chemical yield with a specific activity of 16.6 $\mathrm{Ci} / \mathrm{mmole}$.
The sources and epitopes of antibodies used in this study have been described in detail previously [13].

\section{Cell culture}

HEK293 cells were obtained from ATCC and cultured under standard conditions in Dulbecco's modified Eagle's media supplemented with $10 \%$ fetal bovine serum. The cells were treated for $6 \mathrm{~h}$ with vehicle or Thiamet $\mathrm{G}$ in $1 \%$ DMSO, followed by lysing and harvesting in a buffer containing $50 \mathrm{mM}$ Tris (pH 8.0), $250 \mathrm{mM} \mathrm{NaCl}, 5 \mathrm{mM}$ $\mathrm{KCl}, 2 \mathrm{mM}$ EDTA, 2 mM EGTA, 0.2\% Tween 20, $1 \mu \mathrm{M}$ PUGNAC (Sigma-Aldrich) and 1 tablet of EDTA-free protease inhibitor cocktail (Roche) per $10 \mathrm{~mL}$ of buffer.

\section{Animal experiments}

All animal studies were conducted in an AAALACaccredited facility in accordance with policies of the Merck Institutional Animal Care and Use Committee and the National Research Council's Guide for the Care and Use of Laboratory Animals.

\section{rTg4510 mouse studies}

rTg4510 mice were bred by crossing the hTau responder line (FVB/N strain) and the tTA activator line (129S6 strain) as described previously [11]. In our previous study, we found a significant difference in the agedependent development of tau pathology between male and female rTg4510 mice [13]. To minimize this source of variability, only F1 female rTg4510 mice (FVB/129S6 strain) were used [13] and the study was designed with $80+\%$ power to detect a $30 \%$ effect of Thiamet G administered between 8 and 16 weeks of age and 50-60\% power to detect a $30 \%$ effect of Thiamet $\mathrm{G}$ administered between 12 and 16 weeks of age. For the chronic efficacy studies, Thiamet $\mathrm{G}$ was added at a concentration of $3.3 \mathrm{mg} / \mathrm{g}$ to normal mouse chow (D01060501, Research Diets, Inc., New Brunswick, NJ) to achieve in-diet dosing of $\sim 500 \mathrm{mg} / \mathrm{kg} /$ day. The normal mouse chow without added Thiamet $\mathrm{G}$ was used as the control diet. The control diet was provided ad libitum to all animals beginning at 6 weeks of age. For Thiamet G-treated groups ( $n=35$ per group), the diet was switched to chow containing Thiamet $\mathrm{G}$ at either 8 weeks of age (8 weeks of dosing) or 12 weeks of age ( 4 weeks of dosing). The vehicle-treated group ( $n=35$ per group) received control diet throughout the study. All animals were

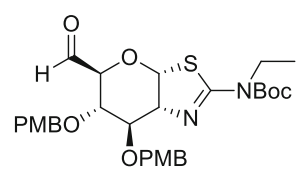

1

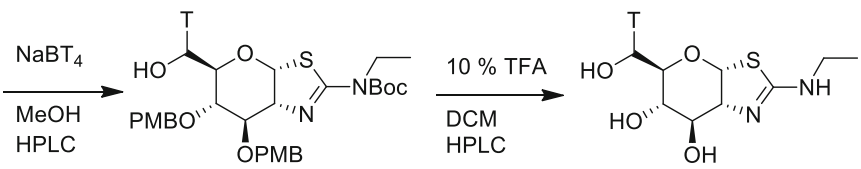

2

$\left[{ }^{3} \mathrm{H}\right]$ Thiamet G 
euthanized at 16 weeks of age. In addition, two baseline groups that were not treated with Thiamet $G$ were euthanized at 8 and 12 weeks of age ( $n=10$ per group). Body weight and food consumption were measured weekly during the study.

\section{Preparation of homogenates, soluble fraction and insoluble fraction from brain}

The brain homogenates and the soluble and insoluble brain fractions were prepared as described previously [13] with some modifications. Briefly, the brain homogenates were prepared by homogenizing each brain hemisphere in $900 \mu \mathrm{L}$ of ice cold buffer comprised of $50 \mathrm{mM}$ Tris (pH 8.0), $250 \mathrm{mM} \mathrm{NaCl}, 5 \mathrm{mM} \mathrm{KCl,} 2 \mathrm{mM}$ EDTA, $2 \mathrm{mM}$ EGTA, $1 \mu \mathrm{M}$ PUGNAC (Sigma-Aldrich) and 1 tablet each of Phos-Stop (Roche) and EDTA-free protease inhibitor cocktail (Roche) per $10 \mathrm{~mL}$ of buffer. The brain homogenate was then centrifuged at $15,000 \mathrm{~g}$ for $15 \mathrm{~min}$ at $4{ }^{\circ} \mathrm{C}$, and the resulting supernatant (designated in this study as total brain homogenate) was centrifuged at $100,000 \mathrm{~g}$ for $30 \mathrm{~min}$ at $4{ }^{\circ} \mathrm{C}$. The supernatant and pellet from this high speed spin are designated in this study as the soluble and insoluble fraction, respectively.

\section{O-protein assay}

A sandwich immunoassay was used to assess total Oprotein. Five $\mu \mathrm{g} / \mathrm{mL}$ biotinylated wheat germ agglutinin (WGA, Vector Biology) in $50 \mu \mathrm{L}$ phosphate-buffered saline (PBS) containing 5\% Blocker A (MSD) and 0.2\% Tween 20 was used to coat 96-well avidin plates (MSD). After incubation for $1 \mathrm{~h}$ at room temperature, the plates were washed three times with $0.2 \%$ Tween 20 in PBS. Twenty five $\mu \mathrm{L}$ of total brain homogenate or cell lysate ( $100 \mu \mathrm{g}$ protein) were then added and the plates were incubated for 3 hours at room temperature before being washed three times with $0.2 \%$ Tween 20 in PBS. This procedure captures glycosylated proteins containing terminal $\mathrm{N}$-acetylglucosamine modification [31, 32]. Subsequently, an antibody that recognizes O-GlcNAc moieties on the captured proteins (RL2, 1:1000 dilution, Abcam) [33] and S-tagged goat anti-mouse antibody (MSD) were added in $50 \mu \mathrm{L}$ of $5 \%$ Blocker $\mathrm{A}$ and $0.2 \%$ Tween 20 and the plates were incubated at $4{ }^{\circ} \mathrm{C}$ overnight. The plates were then washed three times with Wash Buffer (MSD), $150 \mu \mathrm{L}$ Read Buffer T (MSD) was added, and the plates were analyzed on Sector 6000 Imager (MSD).

\section{OGA equilibrium binding assay}

On the day binding assays were performed, the brain homogenates (prepared as described above) were thawed on ice and adjusted to a protein concentration of $0.6 \mu \mathrm{g} / \mathrm{uL}$ with binding assay buffer (BAB; $20 \mathrm{mM}$ HEPES (pH 7.4), $100 \mathrm{mM} \mathrm{NaCl}, 3 \mathrm{mM} \mathrm{MgCl}_{2}, 0.1 \%$
BSA). Assay reactions (500 $\mu \mathrm{L}$ final volume) were assembled at room temperature in 96 deep-well assay blocks (2 mL volume/well) by combining $180 \mu \mathrm{L}$ $\mathrm{BAB}, 20 \mathrm{uL} \mathrm{BAB}$ with or without $20 \mu \mathrm{M}$ unlabeled Thiamet-G (to determine non-specific binding), and $50 \mathrm{uL}$ BAB containing 0-300 $\mathrm{nM}\left[{ }^{3} \mathrm{H}\right]$ Thiamet G. The reactions were then initiated by adding $250 \mu \mathrm{L}$ of brain homogenate and incubated at room temperature for $4 \mathrm{~h}$ with gentle agitation. The reactions were terminated by aspiration via a Brandel tissue harvester onto Unifilter GF/B Whatman filter plates pre-soaked for $30 \mathrm{~min}$ in ice cold $50 \mathrm{mM}$ Tris ( $\mathrm{pH} \mathrm{7.4),0.3 \%} \mathrm{v/v}$ polyethyleneimine. The plates were rapidly washed with ice-cold $5 \mathrm{mM}$ Tris- $\mathrm{Cl}(\mathrm{pH}$ 7.4) before being dried and the plate bottoms sealed. Radioactivity bound to the filter plate was counted on a TopCountNXT scintillation spectrophotometer (PerkinElmer) after adding 60-70 $\mu \mathrm{L}$ Microscint-20 (Perkin Elmer) per well. $K_{d}$ and $B_{\max }$ values for $\left[{ }^{3} \mathrm{H}\right]$ Thiamet $G$ binding to OGA in brain were determined by averaging replicates of total and non-specific binding and simultaneously fitting the mean values to equations describing these parameters [34].

\section{O-tau assay}

The total brain homogenates, as well as the soluble and insoluble fractions from rTg4510 or C57BL6 mouse brain, were prepared as described above. O-GlcNAcylated tau protein (O-tau) in these brain samples was determined as shown in Fig. 7a. For removal of N- and/or O-linked glycans, mouse brain samples ( $300 \mu \mathrm{g}$ protein) were precipitated by standard methanol/chloroform extraction [35] and re-suspended in $30 \mu \mathrm{L}$ of buffer containing 1\% SDS and $20 \mathrm{mM}$ HEPES ( $\mathrm{pH}$ 7.9). Sample volumes were brought to $240 \mu \mathrm{l}$ with $20 \mathrm{mM}$ HEPES, ( $\mathrm{pH}$ 7.9) (without SDS) and $30 \mu \mathrm{L}$ of a denaturing solution containing $1 \%$ octyl-beta-D-glycopyranoside/0.005\% 2-mercaptoethanol (both from Sigma-Aldrich) were added. The samples were then boiled for $5 \mathrm{~min}$ and rapidly cooled on ice. A final $30 \mu \mathrm{L}$ of a solution of $10 \%$ Triton-X100 in 20 mM HEPES $(\mathrm{pH})$ was added to neutralize the remaining SDS, followed by addition of 5 units of the glycoamidase PNGase F (Sigma-Aldrich) to remove N-linked glycans [36]. The reactions were incubated at either $37^{\circ} \mathrm{C}$ for $3 \mathrm{~h}$ or at $4{ }^{\circ} \mathrm{C}$ overnight. In some cases, O-linked glycans were also removed after precipitating the completed PNGase F reaction and resuspending the proteins in water, followed by alkali-mediated $\beta$-elimination using a commercially available kit (Sigma-Aldrich). The $\beta$-elimination reaction proceeded overnight at $4{ }^{\circ} \mathrm{C}$, after which the reactions were carefully neutralized using $1 \mathrm{M} \mathrm{HCl}$.

Following the removal of $\mathrm{N}$ - and/or O-linked glycans, samples were re-precipitated with methanol-chloroform as described above and solubilized in $50 \mu \mathrm{L}$ of $1 \%$ SDS/ 
$50 \mathrm{mM}$ Tris- $\mathrm{Cl}$ ( $\mathrm{pH} 8.0)$. The terminal $\mathrm{N}$-acetyl-betaD-glucosamine (GlcNAc) residues of glycoproteins present in mouse brain samples were labeled with $\mathrm{N}$ azido-galactose using a Click-IT kit according to the manufacturer's instructions (Invitrogen catalog \#33368). Alkyne-conjugated tetramethylrhodamine (TAMRA) was added to the resulting azide by means of coppercatalyzed Huisgen cycloaddition using a commercial kit (Invitrogen). After assembling the reactions as directed by the kit protocol, the reaction tubes were protected from light and rotated at room temperature for $20 \mathrm{~min}$. The reactions were then precipitated with methanol-chloroform as described above and the pellets were solubilized in $75 \mu \mathrm{L}$ of homogenization buffer.

TAMRA-labeled tau protein was immunoprecipitated using biotinylated anti-human tau antibody HT7 (ThermoFisher) followed by capture with streptavidinconjugated magnetic Dynabeads (Invitrogen). Captured TAMRA-labeled tau was then eluted from the beads into $30 \mu \mathrm{L}$ homogenization buffer by heating the samples at $55{ }^{\circ} \mathrm{C}$ for $5 \mathrm{~min}$. The eluted proteins, along with Odyssey infrared size markers (Li-Cor Biosciences), were separated on $12 \%$ Bis-Tris polyacrylamide gels (NuPage Novex) in $1 \times$ MOPS running buffer. TAMRA labeled Otau was detected in the gels using a Typhoon Model FLA9000 laser biomolecular imager (excitation $542 \mathrm{~nm}$ ) and Fujifilm LPG emission filter (GE). Data were captured and analyzed using ImageQuant TL software. Following imaging, the gel was transferred onto nitrocellulose membranes and Western blot analysis was performed using the HT7 antibody (1:1000 dilution, ThermoFisher) and ECL anti-mouse secondary antibody (1:2000 dilution, GE Healthcare). The infrared fluorescence of the size markers and chemiluminescence of the samples were captured using an Odyssey Fc Bioimager (Li-Cor Biosciences) at $700 \mathrm{~nm}$ and $480 \mathrm{~nm}$, respectively, and quantified using ImageQuant TL software.

\section{Brain tau assays}

Total tau, p-tau and tau aggregates were measured using sandwich immunoassays on the AlphaLISA platform (Perkin Elmer) as described previously [13].

\section{CSF tau assays}

CSF total tau was measured as described [13] using an AlphaLISA assay with biotinylated HT7 antibody and BT2 antibody (both from ThermoFisher) conjugated to acceptor beads (PerkinElmer). CSF pT181 tau was measured using an immunoassay on the Erenna platform (Singulex) with HT7 as the capture antibody and AT270 as the detection antibody. Assays measuring CSF pT181 tau were carried out in the presence of Halt ${ }^{\mathrm{R}}$ Protease and Phosphatase Inhibitor Cocktail (Thermo Fisher). Assays $(100 \mu \mathrm{l})$ were carried out in 96-well format with each well containing $10 \mathrm{mg}$ capture beads in $50 \mu \mathrm{l} \mathrm{Sin-}$ gulex assay buffer plus $50 \mu \mathrm{l}$ standard peptide or sample $(2 \mu \mathrm{l} \mathrm{CSF}$ from $\mathrm{rTg} 4510)$ diluted in $0.2 \%$ Tween 20 in PBS. Following incubation at $25{ }^{\circ} \mathrm{C}$ for $4 \mathrm{~h}$, the plates were washed according to the manufacturer's instructions using the Biotek-405 Select TS. Twenty $\mu \mathrm{l}$ of AT270 antibody $(50 \mathrm{ng} / \mathrm{mL})$ was then added and the plate was incubated overnight at $25{ }^{\circ} \mathrm{C}$ with shaking. The plate was developed according to the manufacturer's instructions and data analysis was conducted using Sgx link software (Singulex). A standard curve was established using the synthetic peptide APPGQKGQA-TTDSTTDS-TTDS-TTDS-YS-pSer-PG-pSer-PG-pThr-PGSRS (JPT Peptide Technologies), which incorporates sequences recognized by HT7 and AT270 linked together with four molecules of ((N-(3-[2-[2-(3-Amino-propoxy)-ethoxy]ethoxy]-propyl)-succinamic acid) (TTDS; CAS number 723312-72-9).

\section{Determination of Thiamet $\mathrm{G}$ concentrations in brain and plasma}

Brains were homogenized in water at a $1: 3$ weight/ volume ratio using a GenoGrinder homogenizer. Proteins in plasma samples and brain homogenates were precipitated using acetonitrile containing an internal standard. Untreated brain and plasma were used to prepare standards and quality control samples to cover the expected range of Thiamet $\mathrm{G}$ concentrations. After protein precipitation, samples were centrifuged at $5000 \mathrm{~g}$ and the supernatants were collected for LC-MS analysis using a Transcend System HPLC connected to an API 5000 triple quadrupole mass spectrometer (Thermo Scientific).

\section{Statistical analysis}

Correlation and t-test analyses were conducted using Prism 5.0 software (GraphPad). Two-way repeated measures ANOVA followed by Bonferroni post hoc test was used for body weight and food intake analysis.

\section{Additional files}

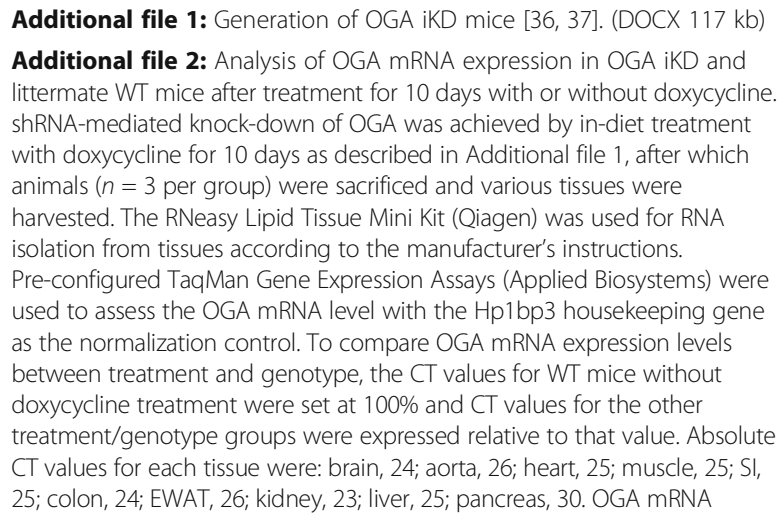


expression was detected in all tissues examined, with particularly high expression levels in brain, colon, and kidney. About 70\% knock-down of OGA mRNA levels was achieved in brain in the OGA iKD mice treated with doxycycline, but a 35\% knock-down of OGA mRNA was also noted for OGA IKD mice that were fed diet without doxycycline, indicating some leakiness in the expression of the shRNA construct in the brain. No other tissue showed evidence of leaky expression of the shRNA construct in the absence of doxycycline treatment. Substantial knock-down of OGA mRNA expression was observed in all tissues in response to doxycycline treatment, with the lowest amount of OGA mRNA remaining in the heart (12\%), kidney (18\%) and liver (25\%). Abbreviations: SI, small intestine; EWAT, epididymal white adipose tissue. (PPTX $99 \mathrm{~kb}$ )

Additional file 3: Detection of O-tau in HEK293 cell lysates and in mouse brain homogenates using antibody 3925 . A. Western blot analysis of O-tau in HEK293 cells. HEK293 cells were transiently transfected with pcDNA3.1 vector alone, with pcDNA3.1 vector containing human 2N4R tau CDNA, or with pcDNA3.1 vectors containing human 2N4R tau CDNA and human OGT. Three days after transfection, cells were treated overnight with $1 \mu \mathrm{M}$ Thiamet $\mathrm{G}$ or vehicle (water). Cells were then lysed as described in Methods, proteins $(10 \mu \mathrm{g})$ were separated by SDS-PAGE and transferred to nitrocellulose, and the nitrocellulose membranes were probed with antibody 3925 (kindly provided by Dr. David Vocadlo at Simon Fraser University, Burnaby, Canada) at a dilution of 1:500 [7]. Purified O-tau from Sf9 cells was also loaded as a control. Antibody 3925 detected O-tau in HEK293 cells only when tau and OGT were coexpressed and the cells were treated with Thiamet G. The antibody also recognized a non-specific protein with similar molecular weight to tau that was present in the vector transfected cells and was not affected by either OGT expression or Thiamet G treatment. B. Western blot analysis of total brain homogenates from wild-type and $\mathrm{rTg} 4510$ mice treated with vehicle, $12.5 \mathrm{mg} / \mathrm{kg}$ or $125 \mathrm{mg} / \mathrm{kg}$ Thiamet G for 7 days. Antibody 3925 did not detect a protein having the molecular weight of O-tau, but did detect a non-specific protein with molecular weight of $37.5 \mathrm{kD}$ that was also present in the brain homogenate from tau knockout mice. (PPTX $247 \mathrm{~kb})$

Additional file 4: Elevation of OGA expression following Thiamet $G$ treatment. rTg4510 mice at 8 weeks of age were treated with vehicle or $100 \mathrm{mg} / \mathrm{kg}$ Thiamet $\mathrm{G}$ formulated in diet for 12 weeks $(n=25$ per group). The brain tissues were analyzed for OGA mRNA level (A) or OGA protein expression using an anti-OGA antibody (Santa Cruz Biotechnology) (B). Both mRNA and protein were elevated $\sim 2$-fold following chronic treatment with Thiamet G. (PPTX $150 \mathrm{~kb}$ )

\section{Abbreviations}

AD: Alzheimer's disease; BAB: Binding assay buffer; CSF: Cerebrospinal fluid; ES cells: Embryonic stem cells; iKD: Inducible knockdown; MSD: MesoScale discovery; NFT: Neurofibrillary tangle; OGA: O-GICNAcGlcNAcase; Oprotein: O-GlcNAc modified protein; O-tau: O-GlcNAcGICNAc modified tau; PBS: Phosphate-buffered saline; PHF: Paired helical filament; PSP: Progressive supranuclear palsy; p-tau: Phosphorylated tau; RCME: Recombinasemediated cassette exchange; SEM: Standard error of the mean; TAMRA: Tetramethylrhodamine; TBS: Tris-buffered saline; WGA: Wheat germ agglutinin; WT: Wild type

\section{Acknowledgments}

We thank Drs. Thomas F. Vogt, Myung K. Shin, John S. Mudgett, Ralph Gareus and Michael Schoor for technical advice on the OGA iKD animal model generation.

\section{Funding}

The work is funded solely by Merck Research laboratories.

\section{Availability of data and materials}

All data generated or analyzed during this study are included in this published article [and its supplementary information files]. Additional information may be requested from corresponding authors and the release is upon approval by Merck Research laboratories.

\section{Authors' contributions}

$\mathrm{NBH}$ designed the ${ }^{3} \mathrm{H}$-Thiamet $\mathrm{G}$ binding assay and O-tau assay, performed data analysis and contributed to the writing of this manuscript. MS and VM developed and validated O-tau assay, and VM performed the O-tau analysis for this manuscript. EJM and HS designed and coordinated the synthesis of ${ }^{3} \mathrm{H}$-Thiamet G. TWR designed and coordinated the generation of OGA iKD mice. MM conducted the OGA mRNA analysis in different tissues. MS performed the ${ }^{3} \mathrm{H}$-Thiamet $\mathrm{G}$ binding and $\mathrm{O}$-tau assays for iKD mouse characterization. $\mathrm{JL}$ and GT developed MSD O-protein assay and JL also contributed to the data in Fig. 1. KLKH performed O-protein analysis in all in vivo studies except that for OGA IKD mice. XW, SXL and LH led the design and execution of the in vivo efficacy studies. LS, GT and OX performed the analysis of different pathological tau species in the brain. XW, LS, LH and LZ also contributed to the analysis of in vivo efficacy data and the writing of the manuscript. DG and GW designed and performed the pharmacokinetic analysis of the in vivo studies and contributed to the writing of the manuscript. MM and LM worked on the CSF pTau assay development and LM performed the CSF pTau analysis. BDB and DL designed the CSF pTau assay and contributed to the writing of this manuscript. CRRH conducted the experiments described in Additional file 3: Figure S3 on antibody 3925 characterization. $\mathrm{JL}$ also performed the experiment in Additional file 4: Figure S4 of OGA protein expression upon treatment with Thiamet G. RH, JFH, EJM, $H S, D J V, J L D, E M P$ and LZ contributed to the strategic design of the studies and the discussion on the data. EMP and LZ coordinated the writing and editing of the manuscript. All authors read and approved the final manuscript.

\section{Authors' information}

Available upon request.

\section{Competing interests}

All authors were employees of Merck Research Laboratories or Alectos Therapeutics at the time of this study.

\section{Consent for publication}

All authors have approved the publication of the studies described in this manuscript.

\section{Ethics approval and consent to participate}

All studies were performed with the approval of Merck Institutional Animal Care and Use Committee under the National Research Council's Guide for the Care and Use of Laboratory Animals.

\section{Publisher's Note}

Springer Nature remains neutral with regard to jurisdictional claims in published maps and institutional affiliations.

\section{Author details}

${ }^{1}$ Department of Neuroscience, Kenilworth, NJ, USA. ${ }^{2}$ Department of In Vivo Pharmacology, West Point, PA, USA. ${ }^{3}$ Department of Molecular Biomarkers, Kenilworth, NJ, USA. ${ }^{4}$ Department of Pharmacokinetics, Pharmacodynamics and Drug Metabolism, Kenilworth, NJ, USA. ${ }^{5}$ Department of Neuroscience, West Point, PA, USA. ${ }^{6}$ Alectos Therapeutics Inc., Burnaby, BC, Canada. ${ }^{7}$ Department of In Vivo Pharmacology, Kenilworth, NJ, USA. ${ }^{8}$ Discovery Chemistry, Merck Research Laboratories, West Point, PA, USA. ${ }^{9}$ Discovery Chemistry Merck Research Laboratories, Kenilworth, NJ, USA.

Received: 26 August 2016 Accepted: 9 May 2017

Published online: 18 May 2017

\section{References}

1. Lee VM, Goedert M, Trojanowski JQ. Neurodegenerative tauopathies. Ann Rev Neurosci. 2001:24:1121-59.

2. Spillantini M, Goedert M. Tau pathology and neurodegeneration. Lancet Neurol. 2013;12:609.

3. Goedert M, Jakes R. Mutations causing neurodegenerative tauopathies. Biochim Biophys Acta. 1739;2005:240-50.

4. Hutton $\mathrm{M}$, Lendon $\mathrm{CL}$, Rizzu P, Baker M, Froelich $\mathrm{S}$, Houlden $\mathrm{H}$, Pickering-Brown S, Chakraverty S, Isaacs A, Grover A, et al. Association of missense and $5^{\prime}$-splice-site mutations in tau with the inherited dementia FTDP-17. Nature. 1998;393:702-5. 
5. Hart GW, Slawson C, Ramirez-Correa G, Lagerlof O. Cross talk between O-GlcNAcylation and phosphorylation: roles in signaling, transcription, and chronic disease. Annu Rev Biochem. 2011;80:825-58.

6. Zhu Y, Shan X, Yuzwa SA, Vocadlo DJ. The emerging link between O-GlcNAc and Alzheimer disease. J Biol Chem. 2014;289:34472-81.

7. Yuzwa SA, Shan X, Macauley MS, Clark T, Skorobogatko Y, Vosseller K, Vocadlo DJ. Increasing O-GlcNAc slows neurodegeneration and stabilizes tau against aggregation. Nat Chem Biol. 2012:8:393-9.

8. Borghgraef $P$, Menuet $C$, Theunis $C$, Louis J, Devijver $H$, Maurin $H$, Smet-Nocca C, Lippens G, Hilaire G, Gijsen H, et al. Increasing brain protein $\mathrm{O}-\mathrm{GlCNAC}$-ylation mitigates breathing defects and mortality of tau.P301L mice. PLoS One. 2013;8:e8442.

9. Graham DL, Gray AJ, Joyce JA, Yu D, O'Moore J, Carlson GA, Shearman MS, Dellovade TL, Hering H. Increased O-GlcNAcylation reduces pathological tau without affecting its normal phosphorylation in a mouse model of tauopathy. Neuropharmacology. 2014;79:307-13.

10. Khanna MR, Kovalevich J, Lee VM, Trojanowski JQ, Brunden KR. Therapeutic strategies for the treatment of tauopathies: hopes and challenges. Alzheimers Dement. 2016;12:1051-65.

11. SantaCruz K, Lewis J, Spires T, Paulson J, Kotilinek L, Ingelsson M, Guimaraes A, DeTure M, Ramsden M, McGowan E, et al. Tau suppression in a neurodegenerative mouse model improves memory function. Science. 2005;309:476-81.

12. Barten DM, Cadelina GW, Hoque N, DeCarr LB, Guss VL, Yang L, Sankaranarayanan S, Wes PD, Flynn ME, Meredith JE, et al. Tau transgenic mice as models for cerebrospinal fluid tau biomarkers. J Alzheimers Dis. 2011;Suppl 2:127-41.

13. Song L, Lu S, Ouyang X, Melchor J, Lee J, Terracina G, Wang X, Hyde L, Hess J, Parker E, Zhang L. Analysis of tau post-translational modifications in $r$ Tg4510 mice, a model of tau pathology. Mol Neurodegener. 2015;10:14.

14. Ramsden M, Kotilinek L, Forster C, Paulson J, McGowan E, SantaCruz K, Guimaraes A, Yue M, Lewis J, Carlson G, et al. Age-dependent neurofibrillary tangle formation, neuron loss, and memory impairment in a mouse model of human tauopathy (P301L). J Neurosci. 2005;25:10637-47.

15. Yuzwa SA, Macauley MS, Heinonen JE, Shan X, Dennis RJ, He Y, Whitworth GE, Stubbs KA, McEachern EJ, Davies GJ, Vocadlo DJ. A potent mechanism-inspired O-GIcNAcase inhibitor that blocks phosphorylation of tau in vivo. Nat Chem Biol. 2008;4:483-90.

16. Yang YR, Song M, Lee H, Jeon Y, Choi EJ, Jang HJ, Moon HY, Byun HY, Kim EK, Kim DH, et al. O-GlcNAcase is essential for embryonic development and maintenance of genomic stability. Aging Cell. 2012;11:439-48.

17. Mandelkow EM, Mandelkow E. Biochemistry and cell biology of tau protein in neurofibrillary degeneration. Cold Spring Harb Perspect Med. 2012;2:a006247.

18. Arnold CS, Johnson GV, Cole RN, Dong DL, Lee M, Hart GW. The microtubuleassociated protein tau is extensively modified with O-linked N-acetylglucosamine. J Biol Chem. 1996;271:26741-4.

19. Morris M, Knudsen GM, Maeda S, Trinidad JC, loanoviciu A, Burlingame AL, Mucke L. Tau post-translational modifications in wild-type and human amyloid precursor protein transgenic mice. Nat Neurosci. 2015;18:1183-9.

20. Yuzwa SA, Shan X, Jones BA, Zhao G, Woodward ML, Li X, Zhu Y, McEachern EJ, Silverman MA, Watson NV, et al. Pharmacological inhibition of O-GlcNAcase (OGA) prevents cognitive decline and amyloid plaque formation in bigenic tau/APP mutant mice. Mol Neurodegener. 2014;9:42.

21. Yu Y, Zhang L, Li X, Run X, Liang Z, Li Y, Liu Y, Lee MH, Grundke-labal I, lqbal K, et al. Differential effects of an O-GlcNAcase inhibitor on tau phosphorylation. PlosOne. 2012;7:e35277.

22. Yuzwa SA, Cheung AH, Okon M, McIntosh LP, Vocadlo DJ. O-GlcNAC modification of tau directly inhibits its aggregation without perturbing the conformational properties of tau monomers. J Mol Biol. 2014;426:1736-52.

23. Hatcher NG, Miller RA, Ke Z, Lee J, Cardasis HL, Terracina G, Zhang L, Marcus J, Wang X, Toolan DM, et al. Discovery proteomics to targeted biomarker assays: identification of tau post-translational modifications that track O-GlcNAcase inhibition by Thiamet G. J Am Soc Mass Spectrom. 2015;26(Supplement 1):52.

24. Yuzwa SA, Yadav AK, Skorobogatko Y, Clark T, Vosseller K, Vocadlo DJ. Mapping O-GlcNAc modification sites on tau and generation of a sitespecific O-GlcNAc tau antibody. Amino Acids. 2011;40:857-68.

25. Marotta NP, Lin YH, Lewis YE, Ambroso MR, Zaro BW, Roth MT, Arnold DB, Langen R, Pratt MR. O-GlcNAc modification blocks the aggregation and toxicity of the protein a-synuclein associated with Parkinson's disease. Nat Chem. 2015;7:913-20.

26. Gambetta MC, Müller J. O-GlcNAcylation prevents aggregation of the Polycomb group repressor polyhomeotic. Dev Cell. 2014;31:629-39.

27. Blennow K, Hampel H, Weiner M, Zetterberg H. Cerebrospinal fluid and plasma biomarkers in Alzheimer disease. Nat Rev Neurol. 2010;6:131-44.

28. Sean M, Smith SM, Struyk A, Jonathan D, Declercq R, Marcus J, Toolan D, Wang X, Schachter JB, Cosden M, Pearson M, et al. Early clinical results and preclinical validation of the O-GICNAcase (OGA) inhibitor MK-8719 as a novel therapeutic for the treatment of tauopathies. Alzheimers Dement. 2016;16:P261.

29. Seibler J, Kleinridders A, Küter-Luks B, Niehaves S, Brüning JC, Schwenk F. Reversible gene knockdown in mice using a tight, inducible shRNA expression system. Nucleic Acid Res. 2007;35:e54.

30. Liu K, McEachern EJ, Mu C, Selnick HG, Vocadlo DJ, Wang Y, Wei Z, Zhou Y, Zhu Y. Selective glycosidase inhibitors and uses thereof, vol. WO2012061972 A1; 2012.

31. Chalkley RJ, Thalhammer A, Schoepfer R, Burlingame AL. Identification of protein O-GIcNAcylation sites using electron transfer dissociation mass spectrometry on native peptides. Proc Natl Acad Sci. 2009;106:8894-9.

32. Di Domenico F, Owen JB, Sultana R, Sowell RA, Perluigi M, Cini C, Cai J, Pierce WM, Butterfield DA. The wheat germ agglutinin-fractionated proteome of subjects with Alzheimer's disease and mild cognitive impairment hippocampus and inferior parietal lobule: implications for disease pathogenesis and progression. J Neurosci Res. 2010;88:3566-77.

33. Snow CM, Senior A, Gerace L. Monoclonal antibodies identify a Group of Nuclear Pore Complex Glycoproteins. J Cell Biol. 1987;104:1143-56.

34. Motulsky HJ, Neubig RR. Analyzing binding data. Curr Protoc Neurosci. 2010; doi:10.1002/0471142301.ns0471140705s0471142352.

35. Wessel D, Flügge UI. A method for the quantitative recovery of protein in dilute solution in the presence of detergents and lipids. Anal Biochem. 1984;138:141-3.

36. Freeze $\mathrm{H}$, Kranz $\mathrm{C}$. Endoglycosidase and glycoamidase release of $\mathrm{N}$-linked glycans. Curr Protoc Mol Biol. 2010;17.14A:1-25.

37. Seibler J, Küter-Luks B, Kern H, Streu S, Plum L, Mauer J, Kühn R, Brüning JC, Schwenk F. Single copy shRNA configuration for ubiquitous gene knockdown in mice. Nucleic Acid Res. 2005;33:e67.

\section{Submit your next manuscript to BioMed Central and we will help you at every step:}

- We accept pre-submission inquiries

- Our selector tool helps you to find the most relevant journal

- We provide round the clock customer support

- Convenient online submission

- Thorough peer review

- Inclusion in PubMed and all major indexing services

- Maximum visibility for your research

Submit your manuscript at www.biomedcentral.com/submit
C Biomed Central 